\title{
Genetic diversity analysis of pumpkin genotypes (Cucurbita moschat Duch ex. Poir) using morphological and RAPD markers
}

\author{
M.S. MURALIDHARA AND N.C. NARASEGOWDA \\ Department of Horticulture, University of Agricultural Sciences, BENGALURU (KARNATAKA) INDIA \\ Email : murali7831@gmail.com
}

\begin{abstract}
The study was conducted to ascertain genetic diversity of 20 pumpkin (Cucurbita moschat Duch ex. Poir) genotypes collected from different parts of India, using morphological and random amplified polymorphic DNA (RAPD) markers. The morphological data recorded for growth and yield characters at different levels. CTAB method used for isolation of DNAs from 20 genotypes. A total of 21 markers produced form 3 primers, out of that one band was polymorphic and remaining once were monomorphic. A dendogram grouped the genotypes into 2 clusters A and B at 9 linkage distance. Cluster B was the major group consisted of 12 accessions, CM-14 genotype which is diverse form other genotypes grouped under cluster B. Cluster B again sub divided into 6 sub groups. The second cluster A consisted of 8 accessions separated at 3 linkage distance and divided into 2 groups. The genetic dissimilarity matrix based on Squared Euclidean Distance, showed a maximum dissimilarity (10\%) between the genotypes Bangalore local-2 and Magadi local and the minimum dissimilarity (1\%) between CO-2 and Solan Badam, CO-2 and Bangalore local-1, KIC-1 and IIHR-5. This analysis showed the potentiality of CM-14 variety due to its less vine length, less number of days to female flower appearance and early maturity as probable parent in hybridization programme.
\end{abstract}

Key words : Cluster analysis, CTAB, Dissimilarity matrix, Genetic diversity, RAPD

How to cite this paper : Muralidhara, M.S. and Narasegowda, N.C. (2014). Genetic diversity analysis of pumpkin genotypes (Cucurbita moschat Duch ex. Poir) using morphological and RAPD markers. Asian J. Bio. Sci., 9 (2) : 188-194. 